\title{
The Pragmatics of Humor: January 25th Revolution and Occupy Wall Street
}

\author{
Bahaa-eddin Abulhassan Hassan
}

Sohag University, Egypt

bahaassan@yahoo.com

Doi:10.5901/mjss.2013.v4n2p551

\begin{abstract}
The study investigates the use of humor by the Egyptian demonstrators in January 25th Revolution and the American demonstrators in Occupy Wall Street Movement. It answers the questions how and why demonstrators use humor. This study explores how humor can be used as a strategy of nonviolent resistance to oppression and dictatorship. The study aims to recognize the pragmatic nature of humor and its explanation according to Grice's Cooperative Principles. It combines linguistic, sociological and psychological theories about humor with theory of speech act. Humor is considered in the study as speech act of declaring resistance to oppression. As a comparative study, it tries to find out the similarities and differences in the two events. Humor seems to have a powerful potential in facilitating outreach and mobilization. The findings of the study provide an outline of the functions of humor as a form of resistance.
\end{abstract}

Keywords: Pragmatics, Humor, Speech act, Implicature, resistance

\section{Introduction}

This is a study of humor in political context: it sets out to uncover the nature of humor in political context by means of a pragmatic approach which draws on certain aspects of conversational implicature and also uses, critically, some of the essential ideas of speech act theory. After beginning with a survey of the main theories of humor, which give us some insight into what lies beneath the surface of humor behavior, there is an in-depth look at the mechanism and function of humor. Both of these reveal the significance of using humor as a form of resistance. The study is not dealing with the linguistic resources available for the creation of humor but it describes the pragmatic nature of humor and illuminates its use in political context as a form of resistance.

The study views humor in political situation as speech act of declaration; it declares resistance and defiance to oppression. Examples from the Egyptian January $25^{\text {th }}$ revolution, which used humorous language as a part of its strategy to bring down Mubarak from power, compared with examples from Occupy Wall Street, serve to explain the dynamics of humor as speech act of declaring resistance. Authentic examples help to explain the role of humor as a political tool. The study aims to answer three central questions concerning the use of humor as speech act of declaring resistance.

1- What theoretical framework is needed in order to understand how humor works?

2- What theoretical framework is needed to explain why humor is used as a form of resistance and a language of defiance to oppression?

3- Does humor as a political tool differ from a culture to another?

To better understand the phenomenon of humor as non-violent resistance, the study does not delimit the concept of humor. Humor here means everything that causes amusement, whether a joke, irony, or satire. The humor investigated in the study is political, only directed against oppression.

\section{Background}

Few studies have focused on humor as a political tool. Sharp (1973) discusses the politics of nonviolent action. Mulkay (1988) explores the nature of humor and its place in modern society. Scott (1990) plays a role in explaining how humor can facilitate a culture of resistance. However, Benton (1988) has paid little attention to humor as a form of active resistance. "The political joke will change nothing ... it reflects no political programme. It will mobilize no one". (1988:54). Al-Arousy (2001) explores the language of humor in affective situations in Arabic and English. Theories about resistance 
have little to say about the role of humor as speech act of declaring resistance. Humor can work to counter oppression. The study explores the use of humor in both theory and practice and there is a need for more practical use of it and more research to help understand it better.

\section{Theoretical Background}

Incongruity, superiority, and relief theories are usually described as the three main approaches to humor. First, incongruity theory is considered the linguistic theory of humor because it is built on the perception or reception of incongruity with the nature of humorous texts. Second, superiority theory reflects a social relationship: the relation between human and aspects of superiority such as power, conflict, or hierarchy is still central to superiority theory. Third, relief theory establishes a relation between humor and the unconscious. Sigmund Freud combined elements of relief and incongruity theory. While incongruity theory is considered as a linguistic theory, superiority is a sociological approach to humor and relief is a psychological one. The study proposes that incongruity theory explains the mechanism of humor occurrence but superiority and relief theories provide the function or the reasons beyond the use of humor.

\subsection{Mechanism of humor (incongruity)}

Incongruity theory is the leading approach. It primarily focuses on the object of humor; it sees humor as a response to an incongruity, a term broadly used to include ambiguity and inconsistence. It focuses on the element of surprise. It states that humor is created out of a conflict between what is expected and what actually occurs in humor. This accounts for the most obvious feature of much humor: an ambiguity, or double meaning, which deliberately misleads the audience, followed by a punchline. Incongruity theory is the dominant theory of humor, since it seems to work in most cases of humor, which is partly because "incongruity" is something of an umbrella term (Latta 1998: 106). Humor is said to have the following elements:

1- a conflict between what is expected and what actually occurs in the joke.

2- An ambiguity at some level of language with semantic or pragmatic meaning or both.

3- A punchline which resolves the conflict.

First, register is an important concept in humor. Humor is produced by the clash between the register used and the register that would be appropriate or expected in a situation. Not all types of humor are context-sensitive. While jokes are context-free and neutral forms of humor, irony is a context-bound and aggressive form of humor. Second, humor has two components, a semantic and a pragmatic one. The semantic component is formed when there is antonymic opposition between two scripts or frames that are compatible entirely or partly with the text. Raskin (1985) discusses the idea of humor competence in his Semantic Script Theory of Humor (SSTH). The main hypothesis of the theory is that a text can be viewed a humorous text if two conditions are met. These are:

i) the text is compatible, fully or in part, with two different scripts.

ii) the two scripts with which the text is compatible are opposite (1985:99).

The semantic theory of humour is...designed to model the native speaker's intuition with regard to humor or, in other words, his humor competence. The theory models and thus defines the concept of funniness...[and] is formulated for an ideal speaker-hearer community i.e. for people whose senses of humor are exactly identical (1985: 58)

The idea of humor competence is more strongly formulated by Attardo (1994).

The SSTH models the humorous competence of an idealised speaker/hearer who is unaffected by racial or gender biases, undisturbed by scatological, obscene or disgusting materials, not subject to boredom, and, most importantly, who has 'never heard it before' when presented with a joke. (1994:197)

Clearly, this is a cognitive model to humor. Raskin calls it 'a mechanical symbol-manipulation device' (1985: 58) which reflects Chomsky's concept of linguistic competence with its 'ideal speaker-hearer' (1965:3). Many jokes are built on the fact that there can be two possible interpretations. If there is double meaning, humor involves a type of incongruity. There are elements of surprise, innovation and rule-breaking. In this respect, irony is different from humor because irony is built on purely pragmatic meaning without a semantic counterpart. Language users (the teller and the tellee) share a set of conventions, if not rules, about how language usually works.

The pragmatic component is constructed when there is a violation of Grice's cooperative maxims. To understand 
the pragmatics of humor the study draws on Grice's cooperation principles. Humor can be seen as conversational implicature. Conversational Implicature is a type of pragmatic inference in which meaning is conveyed through nonconventional means. A few years after Grice's theory of meaning-nn which distinguishes between speaker meaning and sentence meaning, he outlines a theory of conversational implicature which is built on what he called the 'Cooperative Principle' (CP). He proposes that participants in conversation observe some principles to ensure successful communication (Levinson 1983: 101).

The Cooperative Principle

Make your conversational contribution such as is required, at the stage at which it occurs, by the accepted purpose or direction of the talk exchange in which you are engaged.

The maxim of Quality

Try to make your contribution one that is true, specifically:

(i) do not say what you believe to be false

(ii) do not say that for which you lack adequate evidence

The maxim of Quantity

(i) make your contribution as informative as is required for the current purposes of the exchange.

(ii) do not make your contribution more informative than is required

The maxim of Relevance

Make your contributions relevant

The maxim of Manner

Be perspicuous and specifically:

(i) avoid obscurity

(ii) avoid ambiguity

(iii) be brief

(iv) be orderly

According to Grice, participants are assumed to abide by the CP. Since utterances should be relevant to a certain topic, the maxim of Relevance is of particular importance. Participants always connect utterances to establish a certain continuity of sense. Baker (1992) concludes that implicatures "are essential to maintaining the coherence of discourse" (1992: 226-227). She finds similarity between implicatures and coherence (1992: 227).

According to Grice (1967, 1975, and 1978), these maxims are unconsciously used in verbal interaction. Inferences arise from observance or non-observance of these maxims; implied meaning can be inferred via observing or not observing the maxims. Inferences resulting from observing the maxims are called Standard Implicatures (Levinson 1983: 104). They are often deductions from the maxim of Relevance. Non-observance of the maxims can be exploited for communicative purpose. Inferences coming about from deliberate and ostentatious breaching or flouting the CP are called Conversational Implicatures (1983: 104-109). In using humor in political context demonstrators do not obey Grice's maxims blatantly. So they implicate meaning. They depend on mutual knowledge between them and the authority (reflexive communicative intention in Grice's term); they know that their audience knows that their sentences imply something different from the surface meaning or the literal meaning of the form. Thus, the audience can infer implicit meaning (1983: 17, 113). Demonstrators use humor to communicate something. In political contexts they want to contact the authority and resist its oppression. Humor as implicature is produced by the demonstrators and inference is produced by their audience.

People normally obey CP principles when they want to understand and be understood. When they disobey these principles there is misunderstanding, incongruity and duality. This sort of misunderstanding or incongruity is made use of for a certain purpose. Demonstrators are humorous when they play with misunderstanding or incongruity. In this way humor breaks an important rule of language use: that we should try to communicate as clearly as possible. Green (1989) considers "natural language understanding" as synonym of pragmatics. There are possibilities for ambiguity of meaning when there is a gap between the sense and force of the utterance. Misunderstandings happen when a person concentrates on the structural form of the utterance, rather than being aware that it can have various functions. However, Hay (2001) presents a scalar implicature of humor support which is taken to mean communicative implication). The three implicatures are 1. Recognition, 2. Understanding and 3. Appreciation (p.67). Therefore, humor needs to be recognized, understood, and then appreciated.

To support the notion that humor can be viewed within the obedience or non-obedience of Grice's principles Mulkay (1988) presents two terms "the serious mode" and "the humorous mode". In "the serious mode" people share the same world and take for granted that other people see the world the same way as they do. Therefore they are 
cooperative. There is a clear line between what is real and what is unreal. Any contradictions which are considered problematic are treated as a failure in communication. "In the humorous mode" contradictions are not problematic because incongruity is employed for a certain purpose (1988: 22-30). People use humor when they find something different from their expectations. In the political case humor is a sort of expression. People use it when feel that something has changed and they expect further changes. Sorensen (2008) explains that "humor changes the situation because however serious the message is, it has a hint of 'Don't take me seriously,' and 'I am not dangerous'"(2008: 171). Demonstrators who use humor in January $25^{\text {th }}$ and Occupy Wall Street want to wake the people by laughter and make them think about what they want. Humor is indeed a case of turning things upside down to cause amusement. The lack of congruity is what made people laugh. Brigham (2005) explains that through absurdity people can get new insights.

\subsection{Function of humor:}

Concerning the use of humor two theories explain the motives which drive people to use humor: superiority theory and relief theory. According to Superiority theory, and in the words of Thomas Hobbes in his 1651 Leviathan, humor arises from a "sudden glory" felt when we recognize our supremacy over others. Kant (1951) assures that humorous laughter arises from 'the sudden transformation of a strained expectation into nothing' (1951:172). Plato and Aristotle emphasize the aggressive feelings that fuel humor. The theorist Hobbes explained that

"who laugh are momentarily released from awareness of their own lack of ability. This accords with a commonsense perception of much humor being a form of mockery - a way of attacking others, so maintaining power and status by gaining support from others who join in the laughter" (Ross1998: 53).

Representatives of lower social class groups are often the focus of humor. Ross (1998:56) notes that which group is considered to be ridiculous varies from culture to culture.

Jokes and other humorous utterances are a form of communication that is usually shared in social interaction. These humorous utterances are socially and culturally shaped, and often quite particular to a specific time and place. (Kuipers 2008: 1)

Ross (1998:59) shows that powerful groups can be the butt of humor. He explained that "the butt of humour is not always in an inferior position". Much humor is an attack on people in superior positions of power and influence; in a sense, it is the fight-back of the victim, who has only words to use against money, might and status. Satire is an example of this in the public domain. People, who don't have access to the media, collect and spread jokes by word of mouth. There is a consensus among the joke-tellers that they have suffered, in some way, at the hands of these people (Ross 1998: 59). Superiority theory looked at humor as a form of attack. Humor is part of a battle between groups in a society. One of the humor theorists with a sociological insight was Henri Bergson. Laughter has a social function. Bergson did not want to give a psychological explanation of laughter. Instead he explained laughter in functionalist terms: laughter is "a social gesture". This theory can be used to explain the motives beyond the use of humor in the American case because it emphasizes social distance between the tellers, their audience and the butt of humor. Demonstrators have only words to use against money, might and status. In the American case demonstrators had nothing to fear from. However, Egyptian demonstrators were full of fear from the police state in January $25^{\text {th }}$. Egyptian demonstrators had only words to use against dictatorship. Therefore, the study argues that relief theory is suitable to explain the use of humor in the Egyptian case. "Laughter ...liberates from the fear that developed in man during thousands of years: fear of the sacred, of prohibitions, of the past, of power" (Bakhtin 1984:94). Alexander Herzen believed in the revolutionary power of laughter.

According to relief theory, humor expresses some sort of battle within ourselves. It is typically associated with Sigmund Freud and Herbert Spencer, who saw humor as fundamentally a way to release or save energy generated by repression. According to Spencer (1860/1987: 108-109) humor is "the discharge of arrested feelings into the muscular system...in the absence of other adequate channels". However, Spencer lays heavily on the relationship between this energy release and the experience of incongruity (1860/1987: 110). The discharge of tension is one of the main functions of humor according to Sigmund Freud (1905/ 1976). Freud referred to the relation between the teller of the joke, his audience and the butt of the joke: he introduced the social relationship into the analysis of humor. Freud discussed the relationship between humor and taboos in certain community. This theory looks at the areas which are taboos (Ross 1998 :63). Jokes, according to Freud, were a way to break the barriers of a community or the social restrictions. To Freud, these restrictions were mostly sex and aggression. El-Arousy (2001: 46) argues that 
Most obvious and receiving most attention from theorists is the emotional component of humor. As Hallett and Derk claim (1998:137), no theorist ignores the salience of aggression, for example, in humor; ....

Al-Arousy (2001) classified humor into two major types: affiliative and aggressive jokes. Therefore, humor can be seen as an act of aggression.

Although Freud did not consider political jokes, they would seem to fall in his category of hostile or aggressive jokes. Political leaders, their regimes, and policies, seem to be the target of the inherent aggression of these jokes. Freud argues that 'by making our enemy small, inferior, despicable or comic, we achieve in a roundabout way the enjoyment of overcoming him' (Freud 1960:103). When regimes do not allow political criticism, jokes become favored in order to make aggressiveness or criticism possible against persons in exalted positions or who exercise authority. The joke then represents 'a rebellion against authority, a liberation from its pressure' (Larsen 180: 105). According to Freud (1960: 90) jokes may have a purpose (tendentious), and may not have a purpose and are an end in themselves (innocent). "Where a joke is not an aim in itself... there are only two purposes that it may serve ... It is either a hostile joke (serving the purpose of aggressiveness, satire, or defense) or an obscene joke (serving the purpose of exposure)"(1960: 96-97). This explanation is related to Krikmann's explanation. According to Krikmann (2007: 36),

Political jokes in Raskin's book (1985: 222-246) are divided in two classes - denigration jokes and exposure jokes. The basic scripts that represent the first class are DENIGRATION OF A POLITICAL FIGURE (showing him as stupid, indecent, unpopular, hated), .... Other types of exposure in political jokes are EXPOSURE OF POLITICAL REPRESSION (terror and arrests, the lack of political freedom and civil liberties, viz. freedom of speech), EXPOSURE OF SHORTAGES (especially in the former Socialist countries), ....(2007: 36).

\subsection{Humor as speech act of resistance}

This study draws on the relevant items from Grice, Austin, and Searle. A speech act can be classified into direct and indirect. In direct speech acts there is a direct relationship between the form and the function, whereas in indirect speech act the form does not directly reflect its functional use. In Searle's terms, an indirect speech act is a speech act performed by means of another (1979: 60). What is important is how hearers interpret the force of indirect speech acts. Related ideas about indirectness and intent came from Austin, who saw three possible layers of meaning: the locutionary, the illocutionary, and the perlocutionary. What is of particular interest is that the gaps between the layers of meaning are ripe for exploitation by anyone with humorous intent. Austin gives attention to words as actions in context. This view of language as action shows the importance of the role of the other participants in the interaction, the audience. There is a difference between the meaning of certain words $(\mathrm{x})$ and what the speaker intends to convey by using those words, a point of great interest for explaining the phenomenon of humor. This opens up the possibility of considering political humor as indirect speech act of declaration. It can be seen as declaration of resistance against oppression.

Dascal (1985) argues that the revolutionary view of meaning by Grice and Austin can be applicable to humor. Dascal points out that 'Jokes...depend on the existence of [these] sociopragmatic devices that make indirectness possible' (1985:98). He considers three different levels of meaning:

(i) Sentence meaning: understanding a speaker's words

(ii) utterance meaning: understanding those words in their specific reference in the context of the utterance

(iii) speaker's meaning: the speaker's intention of uttering those words in that context(1985: 96)

According to Dascal, Speaker's meaning can be direct or indirect. It is direct when it is identical to the utterance meaning; therefore, pragmatic interpretation can be considered as the 'endorsement' of the utterance meaning by the listener. It is indirect when it is different from the utterance meaning and pragmatic interpretation then is formed from the cues in the context. Jokes efficiently exploit this indirectness; the intended meaning, for Dascal, must be done indirectly, and if it is too explicit, meaning will not be recoverable. This indirectness about humor means that

such an interpretation is actually contributed by the listener more than the speaker himself. In fact, the listener construes that interpretation in the course of hearing the joke, and expects the rest of the story will confirm her interpretation. The comic effect arises when an alternative, non-favoured and therefore non-expected interpretation is revealed, at the punch line, as the correct one. (1985: 97, original emphasis)

To determine the illocutionary force of the utterance which does not contain a performative verb Searle (1976) 
proposes that speech acts be grouped into macro-classes. They should not be classified according to the performative verbs, but according to the relationship between 'the words' and 'the world' (Peccei 1999: 51-53). Speech acts are classified into different types:

1- Declaratives

2- Representatives

3- Commissives

4- Directives

5- Expressives (Levinson 1983: 240).

Declaration is a performative speech act. In addition to distinguishing among speech acts, based on their direction of fit, Strawson (1964) distinguished among world-word speech acts between those which are institutional (e.g., baptism, mariage, opening and closing session, declaring war, etc.) and those which are not.

Humor used by people against their political leaders can be considered as resistance of reality. Resistance by using humor language, though cultural and socially determined in nature, is very similar to the resistance reality offers to physical acts. Using humor as a political tool, citizens reach the conclusion that the legal means for addressing their concerns do not work. They tried petitioning, lobbying, writing letters, going to court, voting for candidates that represented their interests, legal protest, and still their views are ignored. Doing it the 'quiet way' wasn't working. That is why they chose to occupy the streets, take action and use of humor language.

\title{
4. Analysis
}

January $25^{\text {th }}$ revolution played an important role in bringing down Mubarak, providing much of the mobilization that brought 3 million people into Tahrir square after falsification of election results in 2010. It is humor which does not make people laugh out loud, but smile a little and provoke thought; humor is a means of resistance. It is a means out of words. Humor was more like a weapon: an expression of aggression and resistance. Larsen (1980) writes that 'the political joke is a safety valve ... a way in which an oppressed people preserves its sanity' (1980: 3). Shehata (1992: 75) notices that political jokes in Egypt began to be popular since 1952.

\begin{abstract}
MANY familiar with post 1952 Egypt will already know of the tremendous popularity of Egyptian political jokes and the frequency with which they are told. Political jokes are an integral part of Egyptian life and can be heard in government offices by bureaucrats passing the time, in local coffee houses, among friends, and in the homes of millions of urban Egyptians.
\end{abstract}

To maintain a sense of humor has certainly been one of the ways of carrying on life in Egypt. Due to the nature of the normative society, the humor of the youths in Egypt is immediately identifiable as a form of defiance. Egyptians do not lose their sense of humor even in the face of everyday open and bizarre violence on the part of the police. Shehata (1992: 75) argues that the political joke can be found in all countries which are repressed. "What is true of Egypt is true of many societies in which political freedoms are repressed."

As explained in incongruity theory political humor needs some incongruity and absurdity in order to thrive -if things are as people expect then there is little to joke about and no reason to set up satire, parody and irony. In Egypt there was plenty of this incongruity and absurdity between what the politicians said and how ordinary people experienced their lives. One way demonstrators in January $25^{\text {th }}$ created humor was by hanging up posters and painting graffiti all over Egypt.

The banner in figure 1 replaces formal language with informal language to convey a sense of being "fed up". The implied message is "I'm not leaving, I'm not putting down my sign, and I'm not giving up, until you go". Figure 1 represents the idea that there is extra weight of labor: sore hands, indeed, tired, exploited hands of a people increasingly dispossessed by their government. 


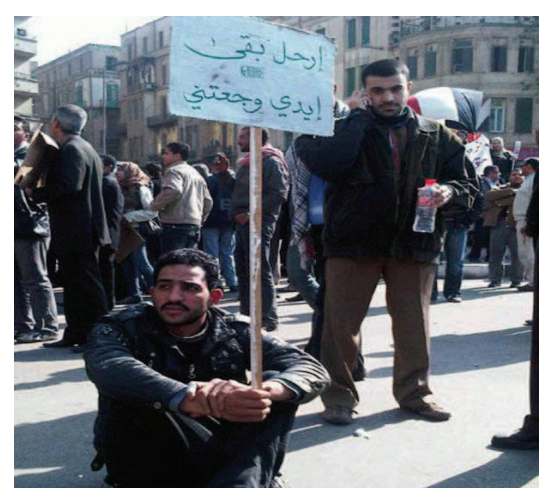

Fig.1 http://www.shbab-2day.com/vb/t95163.html

Similar banners which demonstrators use drew on mundane, daily tasks such as going home as in figure 2 or taking shower as in figure 3 .

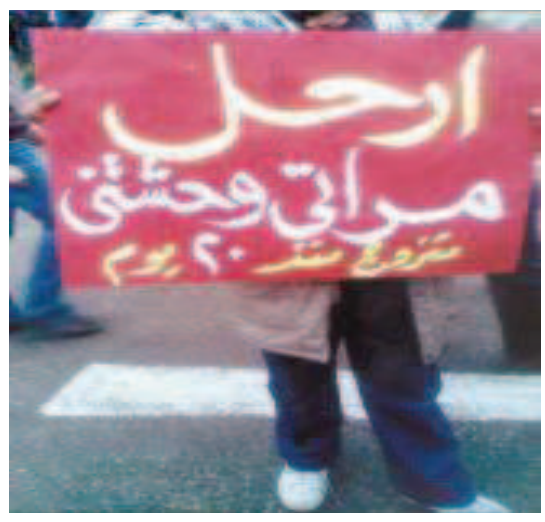

Fig.2 http://digital. ahram.org.eg/articles.aspx?Serial=437385\&eid=6249

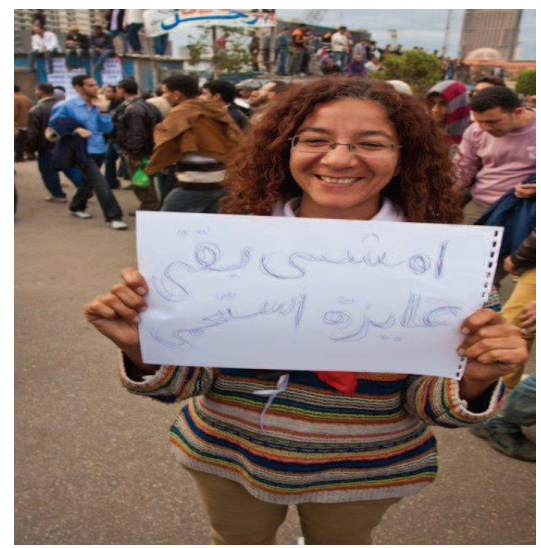

Fig.3 http://www.a7la-shela.com/vb/t16074.html 
Figure 2 and figure 3 show that there is a play with a contrast, because the delay of Mubarak to respond was not the real reason the protestor cannot go home or take shower. The two irrelevant sentences: "Go" and "I want to see my wife" convey a sense of "fed up". The intended meaning is "I am not leaving; I am not putting down my sign, until you go". It is significant that as early as February 1st, protesters started to ridicule the president's persistence to stay in power, ignoring the people's demands and feelings. These banners are written in simple language. They indicate a sense of intimacy, whilst bringing Mubarak down to a level with the people. The banners convey the message that Mubarak hears them, he gets it, but he just won't move. Humor is considered to have been a useful tool in mobilizing and organizing the protests. It provided alternative channels of communication in a situation where mass media was largely controlled by the regime.

People issued a series of jokes, titled "then you are definitely in Egypt" in 2007. Things mentioned in the jokes are difficult to believe, and can only be seen in Egypt. Two examples are mentioned below from the old lists of "then you are definitely in Egypt".

$$
\text { لو رحت تطلع مخالفات عربينك و لاقيتها غير صحيحة لأن بالفعل معندكش عربية .... تبقى انت أكيد في مصر. }
$$

If you went to pay your car fines, because ..... you didn't have a car, then you are definitely in Egypt.

$$
\text { لما تلاقي أمن الدولة عارف صاحبتلك سابتك ليه، وانت لسه متعرفش ..... تبقى انت أكيد في مصر. }
$$

When the state security police know why your girlfriend broke up with you, and you haven't known. Available online: $h$ ttp://www.ebnmasr.net/forum/t43525.html

In fact, this series of joke provide many absurdities in Egypt by presenting grim reality in a humorous way. The frame of the joke refers ironically to the positive side of Egypt as a beautiful place and yet there are still shortcomings. This series of jokes shows many absurdities in the Egyptian revolution by calling attention to real issues and presenting them in a humorous way. Each joke thus contains both positive and negative elements regarding the revolution yet provides a sort of "constructive criticism" in the narrative of the revolution.

Sorensen (2008) mentions 3 functions of humor as a form of nonviolent resistance. First, it facilitates "outreach and mobilization". In other words, humor can attract people who do not belong to the resistance movement. Second, humor facilitates "a culture of resistance" for the members of the resistance movement. Third, humor turns "oppression upside down (2008:175). In his study Sorensen found out that members of the Serbian Otpor movement depended heavily on humor as a part of its strategy to bring down Slobodan Milosevic from power. People found Otpor movement attractive because of humor. Thanks to humor Otpor can attract attention from the media.

In the American case banners in Occupy Wall Street (OWS) were used to stand against the power of the capital society. Humor was also used to bring down the capital system as in the following figures.

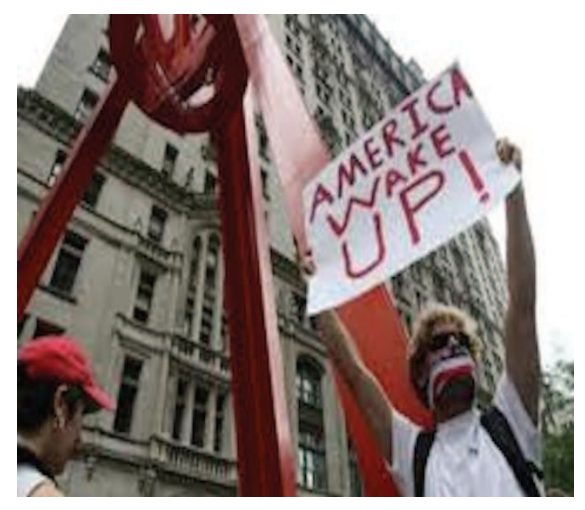

Fig.4 http://sprinterlife.com/2011/10/we-are-the-99-occupy-everywhere.html 
One way Occupy movement created visibility was by hanging up posters and painting graffiti with the symbol of a clenched fist. Posters show that $1 \%$ of Americans owns the nation's wealth.

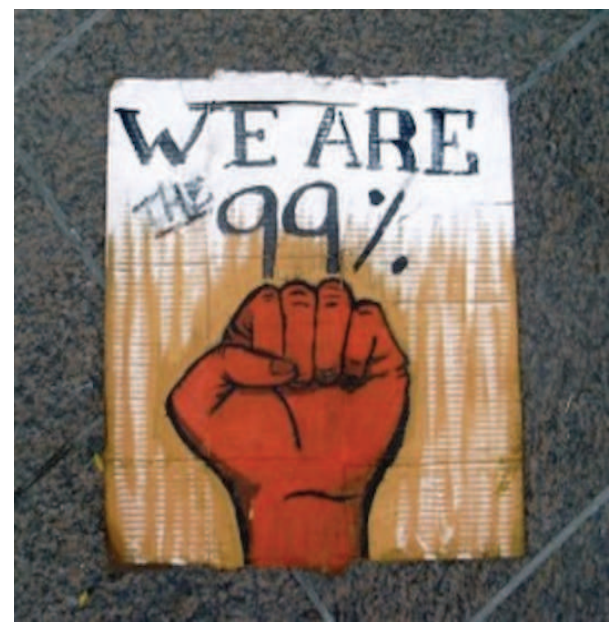

Fig.5 http://sprinterlife.com/2011/10/we-are-the-99-occupy-everywhere.html

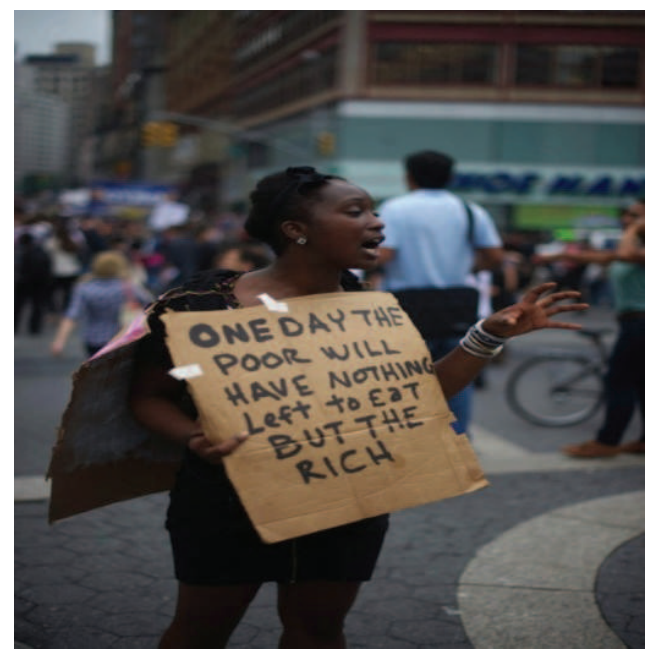

Fig.6 http://www.buzzfeed.com/fjelstud/the-best-signs-from-occupy-wall-street

In Occupy Wall Street, the citizens had reached the conclusion that they are $99 \%$ and they can make a difference in the world. 


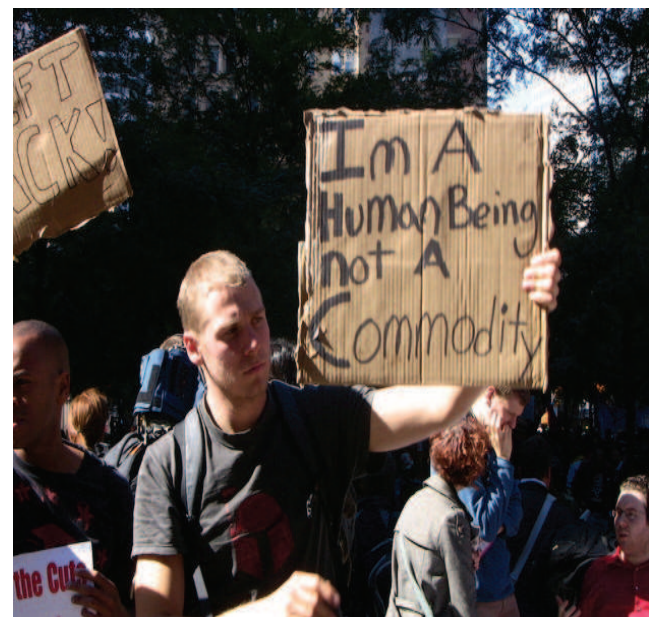

Fig.7 http://www.buzzfeed.com/fjelstud/the-best-signs-from-occupy-wall-street

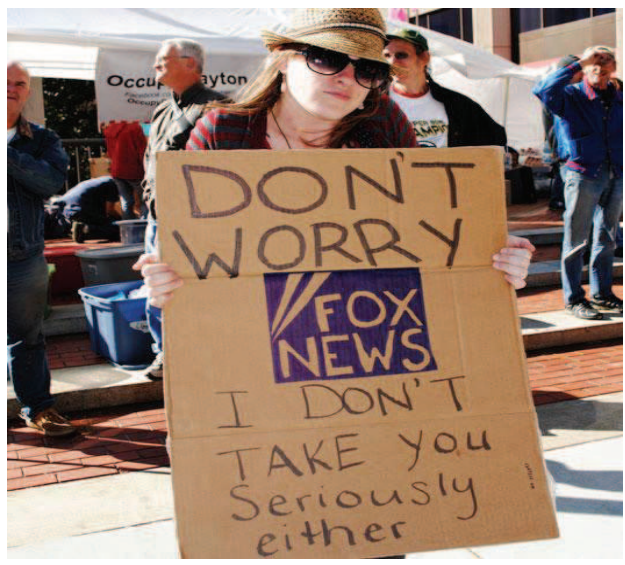

Fig.8http://www.mnn.com/earth-matters/politics/photos/15-funny-signs-from-occupy-wall-street/mutual-disrespect

The study notices that little humor was used by the demonstrators in OWS. Occupy Wall Street was not a special and unusual case of using humor, both when it comes to the amount and the role it played in demonstration.

\section{Cultural Differences}

Naturally, there are differences between cultures. The study contrasts January $25^{\text {th }}$ revolution humor with humor from the United States of America during Occupy Wall Street, finding out that in the Egyptian case there was a culture of fear from the dictator and the oppressed citizen will mock and ridicule the dictator. People in the Egyptian case think of resistance as disobedience to the president who was seen as a god. They understand resistance as giving themselves dignity in the eyes of themselves. Therefore humor was an important factor for reducing people's fear of the regime and of the police. Humor was a part of strategy to provoke Mubarak and reduce people's fear of him. In the case of Occupy Wall Street there was no fear of the regime and the police. People understand resistance as refusal and objection to the state policies. Therefore, superiority theory is the suitable theoretical framework to explain humor in Occupy Wall Street. In the Egyptian case fighting fear was a true element in the humor. Therefore, relief theory is the suitable theoretical framework to explain humor in January $25^{\text {th }}$. The oppressive system was not able to respond to humor. It tried only to call 
demonstrators drug addicts or spies. The nature of January $25^{\text {th }}$ revolution's success was mainly on the psychological level. People were able to challenge the climate of fear and political apathy prevalent in Egypt before January $25^{\text {th }}$.

Symbolic actions, including the use of humor, can have a profound influence if they manage to change people's perception of a situation. A demonstration, a street theatre, or hanging up of a poster has a very different impact in a dictatorial society, where fear dominates, than in a democratic society. Fear is not something one can touch and feel, but it still has a dramatic impact. When someone cases being afraid or is less afraid than before, the situation has changed as long as he or she stats to act differently based on the changed perception of the situation. (Sorensen 2008:185).

Political jokes as speech acts of declaring resistance have existed in repressed societies such as Communist Eastern Europe and modern Egypt. What all of these societies have in common is the repression of their people's political freedoms. And when political freedoms are repressed and open political expression is not tolerated, the political joke becomes a vehicle for the criticism of political leaders, their policies, and government. Humor becomes a form of political protest. People express themselves politically in their jokes and satire. In the case of Occupy Wall Street as an example of nonviolent resistance humor is used so little that it becomes invisible and disappears among all the other factors that play a role in resistance. Americans use humor less often than Egyptians.

\section{Conclusion}

As humor is such a complex cultural phenomenon it requires more investigation. A start was made by surveying the major theories of humor to see the diversity of ideas which various approaches claim underlie humor. Though no single one was found to satisfactorily explain all humor, it is difficult to exclude the aspect of incongruity from humorous occurrences, and so more attention was given to this. This work has used examples of Egyptian and American humorous material to illustrate the relevant linguistic, psychological and social points, drawing on incongruity, relief and superiority theories.

Incongruity theory is the dominant approach which focuses on the object of humor or humorous texts. There must be an element of surprise. It means that humor is produced out of a conflict between what is expected and what actually occurs in humor. This accounts for the nature of humor: an ambiguity which misleads the audience, then followed by a punchline. In humor there must be a conflict between what is expected and what actually occurs in the joke. An ambiguity is created at some level of language with semantic or pragmatic meaning or both. Finally a punchline resolves the conflict.

But the main analysis has focused in great depth on just the pragmatic nature of humor. The study draws on Grice's cooperation principles to help understand the pragmatic nature of humor. Humor can be seen as conversational implicature. The pragmatic element is constructed when humor can be viewed within the non-obedience of Grice's principles. In humorous texts contradictions are considered not problematic because incongruity is employed for a certain purpose. People create humor when they find something different from their expectations. In the political case humor is a sort of expression.

To adequately tackle humor in action a pragmatic approach is needed. Some explanation can be provided by the ideas of speech act theory, particularly in its pointing up of indirectness. Political humor can be considered as indirect speech act of declaration. Indirectness depends on the relation between three possible layers of meaning: the locutionary, the illocutionary, and the perlocutionary. The gaps between the layers of meaning can be exploited for humorous function. Speech act theory can be applicable to humor. Three different levels of meaning can be observed in humor: (i) sentence meaning, (ii) utterance meaning, and (iii) speaker's meaning. Speaker's meaning can be direct when it is identical to the utterance meaning. It is indirect when it is different from the utterance meaning and pragmatic interpretation then is formed. Humorous texts exploit this indirectness.

Humor in political contexts can be seen as a form of resistance to oppression. While demonstrators laugh, they also cope with anger and stress in a positive way. Humor generally does not involve ridicule, deprecation, or humiliation, but aggression is not absent; rather, it has been masked. In general, disempowered members of a culture are restricted from the expression of their anger because it would be perceived by the dominant forces as a direct threat, so anger is either repressed or expressed in seemingly nonthreatening ways. Although expression of anger through humor presumably represents no threat to the status quo, any self-expression of resistance remains empowering and signifies a rejection of oppression. In general, demonstrators release anger and aggression subtly and indirectly. 
The case of $25^{\text {th }}$ revolution has proven that it is a special and unusual case, both when it comes to the amount of humor and the role it played. Humor in January $25^{\text {th }}$ was resistance to a culture of fear from the dictator and demonstrators try to resist oppression. Therefore humor was an important factor for reducing people's fear of the regime and of the police. Therefore, the study depends on relief theory to explain the use of humor in the Egyptian case. In the case of Occupy Wall Street there was no fear of the regime and the police. Demonstrators use humor as refusal and objection to the state policies. Therefore, superiority theory is best used theory to explain humor in Occupy Wall Street.

\section{References}

Al-Arousy, Nahwat. 2001. "Humor in Affective Situations: A Contrastive Study of Arabic and English". In Philology vol. XXXV, pp. 45-82.

Attardo, Salvatore. 1994. Linguistic Theories of Humor. Berlin/New York: Mouton De Gruyter.

Baker, M. 1992. In Other Words: A coursebook on translation. London and New York: Routledge.

Bakhtin, Mikhail. 1984. Rebelais and His World. Bloomington: IndianaUniversity Press.

Benton, Gregor. 1988. "The Origins of the Political Joke". In Humor in Society: Resistance and Control, ed. Chris Powell and George E. C. Paton. New York: St. Martin's Press.

Bergson, Henri. 2005 [1900]. Laughter: An Essay on the Meaning of the Comic. Dover Publications.

Brigham, Stephen. 2005. "Limitations of Reason and Liberation of Absurdity: Reason and Absurdity as Means of Personal and Social Change. Case Study: Psychotherapy". PhD thesis, Wollongong, NSW: University of Wollongong.

Chomsky, Noam. 1965. Aspects Of The Theory Of Syntax. CambridgeMA: The MIT Press.

Dascal, Marcelo. 1985. "Language Use In Jokes And Dreams: Sociopragmatics vs Psychopragmatics". Language and Communication 5.2 .

Freud, Sigmund. 1960. Jokes and Their Relation to the Unconscious. New York: Norton

Grice, H.P. 1967a. "Logic and Conversation". In P. Cole and J.L. Margan (1975), Syntax and Semantics 3. New York: Academic Press, 41-58.

1967b. "Further notes on Logic and Conversation". In P. Cole, (1978), Syntax and Semantics 3. New York: Academic Press, $113-28$

Green, G. 1989. Pragmatics and Natural Language Understanding. Hillsdale, NJ: Lawrence Erlbaum Associates.

Hallett, R.A. and Derks, P. 1998. "Humor Theory and Rabelais". In Humor vol. 11-2, pp. 135-160.

Hay, Jennifer. 2001. "The Pragmatics Of Humor Support". Humor 14 (1): 55-82.

Kant, Immanuel. 1951. Critique Of Judgement. New York: Hafner Publishing Company.

Krikmann, Arvo. 2007. "Contemporary linguistic theories of humour". Folklore. Electronic Journal of Folklore, 33, 27 - 57.

Kuipers, Giselinde. 2008. "The sociology of humor". In Raskin, Victor (ed.) The Primer of Humor Research, pp. $365-402$. Berlin/New York: Mouton de Gruyter.

Larsen, Egon. 1980. Wit as a Weapon: Political Joke in History. London: Frederick Muller Ltd

Latta, Robert L. 1998. The Basic Humor Process: 106, Berlin: Walter de Gruyter.

Levinson, S.C. 1983. Pragmatics. Cambridge: CambridgeUniversity Press.

Monro, D. H. 1988. "Theories of Humor." In Laurence Behrens and Leonard J. Rosen, eds. Writing and Reading Across the Curriculum 3rd ed. Glenview, IL: Scott, Foresman and Company, 349-55.)

Mulkay, M. J. 1988. On Humor: Its Nature and Its Place in Modern Society. Cambridge, UK: Polity Press.

Peccei, J. 1999. Pragmatics. London and New York: Routledge.

Raskin, Victor. 1985. Semantic Mechanisms of Humor. Dordrecht\&Boston\&Lancaster: D. Reidel Publishing Company.

Ross, Alison. 1998. The language of Humor, Routledge

Scott, James C. 1990. Domination and the Arts of Resistance: Hidden Transcripts. New Haven, CT: YaleUniversity Press.

Searle, J. 1969. Speech Acts: An Essay in the Philosophy of Language. Cambridge: Cambridge university Press.

— 1976. "The Classification of Illocutionary Acts". In Language in Society 5. 1-24

Sharp, Gene. 1973. The Politics of Nonviolent Action. Boston: P. Sargent Publisher.

Shehata, Samer. 1992. "The Politics of Laughter: Nasser, Sadat, and Mubarek in Egyptian Political Jokes". Folklore vol. 103:i,. pp, 75-91

Sorensen, Majken Jul. 2008. "Humor as a Serious Strategy of Nonviolent Resistance to Oppression". PEACE \& CHANGE, Vol. 33, No. 2, Peace History Society and Peace and Justice Studies Association

Spencer, Herbert. 1860. The Physiology of Laughter. Macmillan's Magazine 1: 395-402. Spielberger, Charles D. (ed.)

Strawson, P. F. 1964. 'Intention and convention in speech acts', The Philosophical Review 73: 439-60, reprinted in Strawson, Logico-Linguistic Papers. London: Methuen, 1971.

Thomas, J. 1995. Meaning in Interaction: an introduction to Pragmatics. London and New York: Longman. 